\title{
Correction to: Intracellular distribution of new tacrine analogues as a potential cause of their cytotoxicity against human neuroblastoma cells SH-SY5Y
}

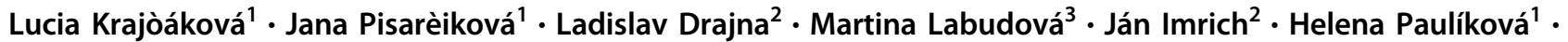 \\ Mária Kožurková ${ }^{2,4}$
}

Published online: 29 March 2019

(c) Springer Science+Business Media, LLC, part of Springer Nature 2019

\section{Correction to:}

Medicinal Chemistry Research (2018) 27:2353-2365

https://doi.org/10.1007/s00044-018-2241-6

The original version of this article unfortunately contained a mistake in author names. The given name and family name was swapped erroneously for all the authors and published incorrectly.

The correct author names should read as Lucia Krajōáková, Jana Pisarèiková, Ladislav Drajna, Martina Labudová, Ján Imrich, Helena Paulíková, Mária Kožurková.
The original article can be found online at https://doi.org/10.1007/ s00044-018-2241-6.

\section{Mária Kožurková}

maria.kozurkova@upjs.sk

1 Department of Biochemistry and Microbiology, Faculty of Chemical and Food Technology, Radlinského 9, Bratislava 81237, Slovakia

2 Department of Biochemistry, Institute of Chemistry, P.J. Safarik University, Moyzesova 11, Košice 04001, Slovakia

3 Slovak Academy of Sciences, Institute of Virology, Dúbravská cesta 9, Bratislava 84505, Slovakia

4 Biomedical Research Center, University Hospital Hradec Kralove, Sokolovska 581, Hradec Kralove, Czech Republic 